\title{
Using Cogenerative Dialogues to Transform Contradictions in Project-Based Learning
}

\author{
Pei-Ling Hsu ${ }^{1 *}$, Yi-Yu Liao ${ }^{1}$ \\ ${ }^{1}$ University of Texas at EI Paso, USA
}

Received 14 March 2018 - Revised 1 May 2018 - Accepted 31 July 2018

\begin{abstract}
Project-based learning ( $\mathrm{PBL}$ ) has been suggested as an effective way to engage students meaningfully in science learning. However, there are many challenges when implementing PBL in teaching and learning (e.g., difficulty of assessing learning, students' hesitation to seek help). This qualitative study investigated how cogenerative dialogues (cogens) can serve as a pedagogical tool to enhance the quality of teaching and learning in a PBL-styled student-scientist partnership program. Data sources included video recording of the internship and cogen activities, field notes, pictures, student journals, and individual interviews. Drawing on cultural-historical activity theory, we identified contradictions tangled with the complex interactions in activities that promoted changes and new developments in teaching and learning. Our analysis of two case studies suggests that cogens help students transform the contradictions in their activity systems into opportunities for becoming active learners, critical thinkers, and collaborative researchers. For transformation to occur, the contradictions must be recognized, reflected, and acted upon. The purposeful discussion about various contradictions in cogens allows participants to deeply reflect on their understandings about learning, teaching, and scientific practice and to disrupt their existing paradigms in order to negotiate new meanings and understandings to support students' science learning.
\end{abstract}

Keywords: project-based learning, cogenerative dialogues, cultural-historical activity theory, contradiction, student-scientist partnership, authentic scientific practices

\section{INTRODUCTION}

In the past 50 years, more than half of America's sustained economic growth came from only about $5 \%$ of U.S. workers who were employed in STEM fields (Babco, 2004). According to the U.S. Department of Labor, employment in STEM occupations grew twice as much as non-STEM occupations between May 2009 and May 2015, and there were nearly 8.6 million STEM jobs in 2015 (Fayer, Lacey, \& Watson, 2017). However, America seems to fall behind with a rapidly increasing demand and global competition of skilled worker in STEM fields. In 2011, for example, only $13 \%$ of the U.S. students chose a STEM major in college, compared with Singapore, where nearly $50 \%$ of students majored in STEM programs (Worsham, Clevenger, \& Whealan-George, 2016). As a result, when the Next Generation Science Standards (NGSS; NGSS Lead States, 2013) were introduced, one of the major shifts from previous science standards was to advocate teaching science as a practice in the real-world environment (Osborne, 2014). One such curricular approach with the goal to engage students with scientific concepts is project-based learning (PBL), "a systematic teaching method that engages students in learning knowledge and skills through an extended inquiry process structured around complex, authentic questions and carefully designed projects and tasks" (Markham, Larmer, \& Ravitz, 2003, p. 4). During the learning process of PBL, students are able to learn science through engaging in meaningful scientific questions, scientific inquiry, and collaboration (Krajcik \& Czerniak, 2014).

(C) 2018 by the authors; licensee Modestum Ltd., UK. This article is an open access article distributed under the terms and conditions of the Creative Commons Attribution License (http://creativecommons.org/licenses/by/4.0/).

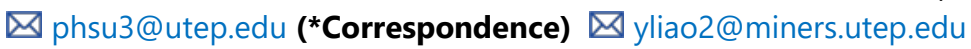




\section{Contribution of this paper to the literature}

- In this study, we pioneered the use of cogens in student-scientist partnerships to support project-based learning.

- Our findings suggest that cogens can serve as a practical instructional design and pedagogical tool to transform challenges and contradictions into teaching and learning opportunities in a project-based learning environment.

- The findings of this study can serve as resources for science teacher education programs and professional development programs for science teachers to learn the use of cogens in their inquiry based teaching practice.

However, there are many challenges when implementing PBL. First, designing an appropriate and meaningful PBL environment involves complex planning and coordination. To facilitate a successful PBL environment requires additional attention to assessing students' prior knowledge, aligning project complexity with students' level, providing proper assistance, and increasing students' teamwork skills (Tseng, Chang, Lou, \& Chen, 2013). Therefore, researchers have called for studies to illustrate how teachers and students can create contexts that support PBL approaches (e.g., perceived classroom goal structure, grouping practices) for teachers to create challenging work in collaboration with their students (Meyer, Turner, \& Spencer, 1997). Second, it is challenging to change the status quo of students' passive leaning mode. Although the findings from recent studies have shown that PBL facilitates the adoption of skills associated with self-regulated learners (Savin-Baden, 2007; Stefanou, Stolk, Prince, Chen, \& Lord, 2013), one of the barriers for students to succeed in a self-regulated learning environment is that students have grown accustomed to a passive environment in which they are often told what to learn and how to do it by teachers in schools (Hao, Branch, \& Jensen, 2016). Thus, researchers have urgently called for more empirical studies that investigate practical instructional design with components of self-regulated learning activities, such as goal setting, self-monitoring, and reflecting on their own learning (Hao et al., 2016). Third, in PBL, being able to ask questions, engage in discussions, and request appropriate assistance from experts are important skills to succeed in completing projects; however, students may be intimidated by teachers' authority and hesitate to ask questions or seek help (Cardoso, Eriş, Badke-Schaub, \& Aurisicchio, 2014; Zydney, deNoyelles, \& Seo, 2012). Finally, teachers and students may encounter unexpected obstacles and difficulties during the process of investigating scientific topics because of PBL's open-ended investigation (Chinowsky, Brown, Szajnman, \& Realph, 2006). The contingent and uncertain nature of PBL may require teachers and students to change their topics or redesign their projects, and so makes the process challenging.

The goal of this study is to introduce cogenerative dialogues (cogens) as a pedagogical tool to address PBL challenges and so improve the quality of teaching and learning for both instructors and students in a PBL-styled science internship. The research question of this study is: "How do cogenerative dialogues transform challenges in PBL into opportunities for learning and growth?"

\section{THEORETICAL FRAMEWORK}

\section{Cultural-Historical Activity Theory}

This study draws on cultural-historical activity theory (CHAT) as a theoretical lens to illustrate the contradictions that shape new developments (Roth \& Tobin, 2002a; Yamagata-Lynch, 2007) and make processes that are usually invisible, visible (Patchen \& Smithenry, 2014). After almost a century of diversification, the CHAT we now know helps research investigators to take "a participatory and interventionist role in the participants' activity to help participants experience change" (Yamagata-Lynch, 2010, p. 23). Since the 1920s, CHAT has evolved through three generations of studies by post-Vygotskian researchers (Engeström, 1996; Yamagata-Lynch, 2010). The first generation was based on Vygotsky's identification of a mediated action triangle in which the simple S-R formula (stimulus-response process) is surpassed by "a complex, mediated act" (Vygotsky, 1978, p. 40). The second generation is attributed to Leont'ev (1974, 1981), who distinguished between the goal-directed action of an individual and the collectively object-oriented activity of a community (Engeström, 2001). In this second generation, Engeström (2001) developed an extended triangular activity system model built on Leont'ev's work in 1987. As described by Stith and Roth (2010), the six basic constituent elements of an activity system include subject (actors engaged in an activity and motivated by the object), object (goal of an activity), tools (cognitive or material resources that the subjects can use to attain the object), rules (norms that regulate subjects' participation), community (group or organization the subjects belong to), and division of labor (shared responsibility for the subjects' participation determined by the community). Finally, the third generation of activity theory takes two interacting activities as a minimal unit of analysis to "develop conceptual tools to understand dialogue, multiple perspectives, and networks of interacting activity systems" (Engeström, 2001, p. 135). 


\section{Contradictions in Activity Theory}

One important principle of CHAT is to underline the contradictions tangled with the complex interactions within and between the activities. The term contradictions here does not merely refer to conflicts and tensions; rather, contradictions are also sources of development (Foot, 2014; Kuutti, 1996). In other words, contradictions are the starting points to open a dialogue aimed at implementing actions and changes toward a desired object or motive while an activity system is continuously evolving (Murphy \& Carlisle, 2008; Roth \& Tobin, 2004). Due to the multivoiced and multifaceted features of activity systems, those contradictions trigger changes and transformations. The internal contradictions become the driving force of development in one's activity system (Engeström, 2001). Thus, while the object or motive manifests actions toward a certain coherence, these internal contradictions also keep the activity systems in constant change. As a result, the participants expand their learning by addressing these challenges collectively in the activity system. Thus, those contradictions become the keys to understanding the factors behind seemingly accidental disputes in collective human activities (Engeström, 2008), and they can be understood at four different levels (Engeström, 1987, 2015). The primary contradiction may exist in each of the six constituent moments of an activity for having its inherent value and exchange value with the society. A secondary contradiction may exist between the moments of an activity. A tertiary contradiction may exist when a more avalanched activity or culture is introduced to the initial activity. A quaternary contradiction may exist between the constituent moments of different interconnected activity systems, and is usually triggered by a tertiary contradiction. Take a doctor's practice, for example (Foot, 2014). A primary contradiction for the doctor (subject) could be the tension between healing patients as effectively as possible (inherent value) and earning income from these patients (exchange value with the society). A secondary contradiction may exist, for example, between the cultural norms (rules) that constrain a doctor from asking questions about patients' sexual behaviors and a diagnostic protocol (tool) that requires a doctor to ask such questions. A tertiary contradiction may exist, for example, when introducing a new nurse into the doctor's practice to improve the treatment quality for patients, because the nurse may question the existing practice and bring new possibilities for change, such as increasing the length of visits to allow more in-depth consultation rather than following the insurance company rule of 15-minute consultations. This tertiary contradiction may trigger a quaternary contradiction: tension between a central activity of the clinic's practice and a neighboring activity of working with an insurance company. These four levels of contradiction allow researchers to better investigate complex, multidimensional activity systems.

In science education, CHAT has been used to understand tool mediation in teaching and learning, to make visible normally invisible structures, processes, relations, and configurations, to investigate issues concerning a larger system or across systems, to rethink and empower science learning, and to create structures and collaborations to facilitate change (Roth, Lee, \& Hsu, 2009). In this study, we draw on CHAT and its conceptions of contradiction to help us better understand the complex and dynamic processes of science learning in high school students' internships with scientists.

\section{RESEARCH CONTEXT}

\section{Research Apprenticeship}

The student-scientist partnerships associated with the Work With A Scientist Program (WWASP) took place at a public university in the southwest United States. Students in WWASP engaged in a seven-month (from January to July) open-ended research project in biology, immunology, chemistry, or engineering. They were doing science at the elbows of scientists who were faculty of the university. Unlike short-term apprenticeships that normally last for 2-8 weeks (Sadler, Burgin, McKinney, \& Ponjuan, 2010), WWASP provided a seven-month timeframe to provide students with sufficient time to become accustomed to a new learning environment and learn science closely and thoroughly in a community of scientists. Moreover, the structure of student PBL projects in WWASP makes authentic science accessible by situating the practices in a meaningful context (Krajcik \& Blumenfeld, 2006) and promoting students' autonomy in their scientific investigation (Radinsky, Bouillion, Lento, \& Gomez, 2001). With the support of scientists and assistants, students in WWASP came up with their research questions and proposals in the Spring semester (from January to May; 11 Saturdays) instead of receiving prescribed questions and methods from their scientists. In addition, students attended the program every other Saturday for a 2-hour internship and a 1-hour cogen session. During Summer semester (from June to July; 6 weeks), students had a 6-hour internship every day from Monday to Friday and two 1-hour cogen sessions per week. In the middle of June, students presented their research project proposals and plans to the public, which included their family members and internal/external judges. Then, they collected and analyzed data with the support of the scientists. At the end of July, they presented their finalized data analysis and results to the public again. An activity system of the internship program is illustrated in Figure 1. 


\section{Activity System of the Work With A Scientist Program}

\section{Tool}

Lectures, handouts, laboratory equipment, online resources, cogenerative dialogues

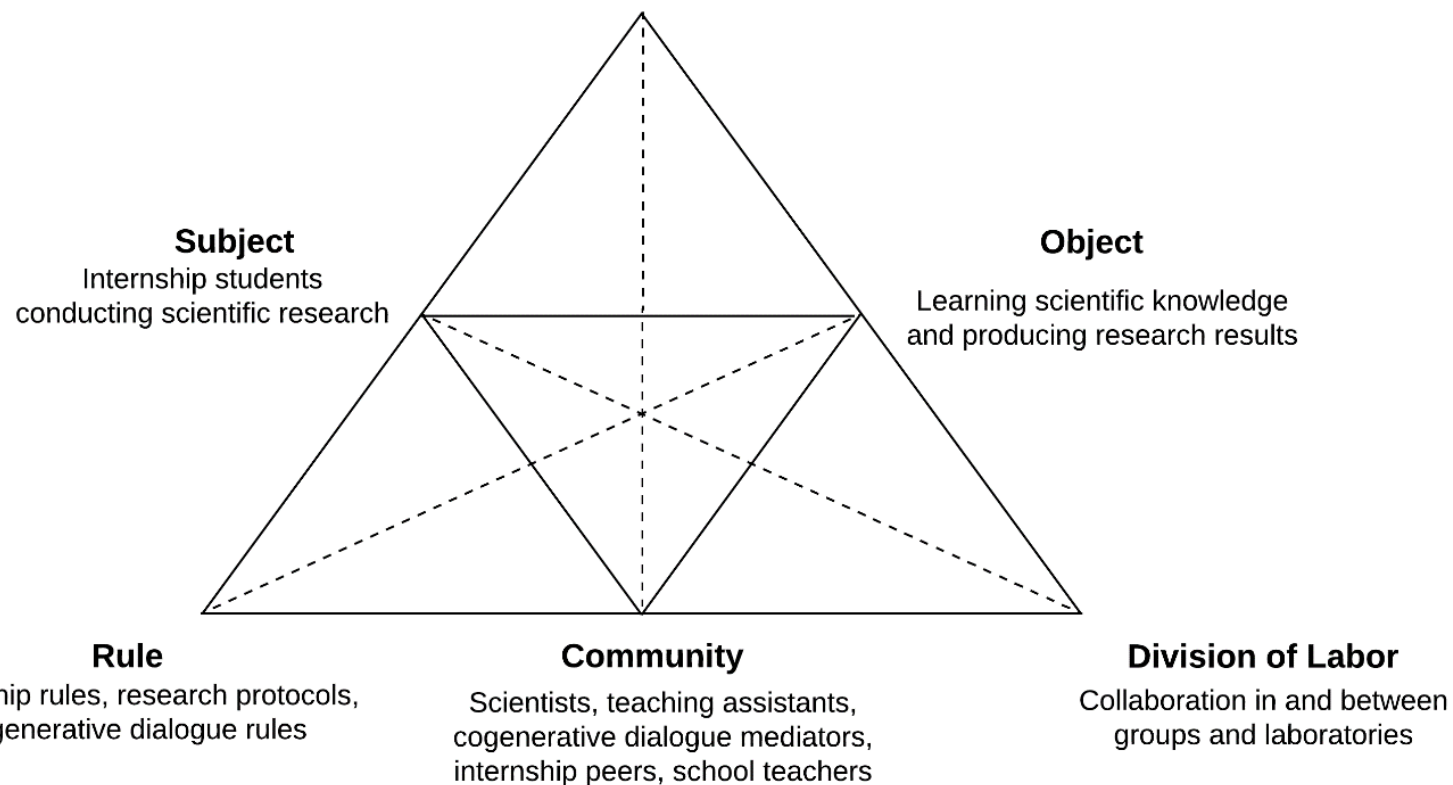

Figure 1. The activity system of the Work With A Scientist Program

\section{Participants}

Thirty-six 11th graders were recruited from three local Title I high schools, in which $48 \%, 57 \%$, and $81 \%$ of the students came from low-income families. The 36 internship students ( 31 Hispanic, 2 Asian, 2 White, 1 Black) were 11 males and 25 females. After admissions, 36 students were divided evenly among four science labs. Each lab was assigned a lead scientist and 2-3 research assistants (RAs) who were undergraduate or graduate students. One of the RAs was an education RA whose role was to mediate cogens between scientists and students to improve their scientific practices. The cogen mediator had received additional training for mediating cogens. The other RAs were science RAs whose job was to assist students with their research in the laboratories. In each lab, students were divided into small groups of 2-3 people. In this study, we targeted two groups (i.e., psychology and chemistry groups) from two different labs (i.e., immunology and chemistry labs) as our case studies because the topics of their cogens covered most of the cogen topics in the other groups. Each group member and their lead scientist in these two case studies was assigned a pseudonym, and their peers and the RAs were assigned with an alphabet letter. More details about the psychology and chemistry groups are presented in the findings.

\section{The Practice of Cogenerative Dialogues}

Cogenerative dialogues (cogens) are conversations held among different stakeholders to reflect their collective experiences, with the goal of reaching collective decisions about the rules, roles, and responsibilities that govern their shared activities (Roth, Tobin, \& Zimmermann, 2002). In each of the four laboratory teams, cogens involved four groups of stakeholders: the lead scientist, science RAs, 9 high school students, and one education RA as a cogen mediator. There are rules associated with cogens so that stakeholders' interactions can be mediated by cogens (Roth \& Tobin, 2002b). Deriving them from general rules implemented to run cogens smoothly in a study of youth in an urban physics classroom (Emdin, 2011), WWASP used the following four rules:

1. Each person has equal turns and times in talking.

2. Each person shows respect and listens attentively in conversations.

3. A plan of action for addressing issues is generated to be implemented in further practice.

4. Video clips of collective practice are available for discussion. 
In addition, to allow cogens to seamlessly mediate dialogues, a three-phase structure was used in cogens (Hsu \& Espinoza, 2018):

o Phase I: Discuss the implementation quality of solutions generated from the previous cogens.

o Phase II: Discuss any issues/positives/topics of the current week.

o Phase III: Discuss the quality of the current cogen by reflecting on three cogen heuristics (Tobin \& Alexakos, 2013).

The cogens focused on identifying issues and generating solutions collectively in order to improve their scientific practice in the internship. In this study, one cogen was defined as a conversation session that reflected on previous internship practice and discussed its quality and areas for improvement. Each cogen normally lasted for one hour, unless participants demanded otherwise. The roles of the cogen mediator were to assist participants in following these rules and to mediate dialogues when necessary. Before the internship program, each cogen mediator received training to learn how to mediate cogens, including reading relevant articles, learning effective mediation strategies (Hsu, 2018), and conducting mock cogen practices.

\section{Data Collection and Data Analysis}

Data sources for this study include about 840 hours of videorecordings of the participants' real-time interactions during the seven-month internship and cogen sessions. In addition, the researchers' field notes, pictures, student journals, and individual interviews on students' internship and cogen experiences were used to validate our findings. After viewing all the data, we chose two groups (psychology and chemistry groups) as our case studies to illustrate the collective efforts to transform contradictions in the internship. There were two students in the psychology group and three students in the chemistry group. These two groups were chosen because they represented different laboratories and their dialogues captured most of the issues shared in the rest of the groups.

Drawing on CHAT as our theoretical framework, we adopted the constant comparative method (Corbin \& Strauss, 2015) to identify contradictions in the internship. First, we conducted open coding sessions to identify all possible categories of contradictions. We went over the videorecordings of participants' interactions during the internship and cogen sessions to identify all possible contradictions. Second, we conducted axial coding to revisit our open codes and generated interconnected categories based on the initial categories. Third, we conducted selective coding to generate the final categories, which formed a storyline based on the interconnected categories. We applied three criteria to help us identify the contradictions in the internship, since not every issue that arose in cogens can be counted as a contradiction in CHAT. First, the issue needs to be consciously brought up during cogens by the participants for discussion. Second, the issue needs to be discussed and agreed on as a collective issue by all cogen participants. Third, the issue needs to be brought up repeatedly in the cogens. In this study, only issues aligned with all three criteria were counted as contradictions in the internship; these contradictions are discussed in the following sections.

To validate the data analysis, we used several techniques from the Fourth Generation Evaluation (Guba \& Lincoln, 1989). To meet Guba and Lincoln's criterion of prolonged engagement, our research team interacted with students, scientists, and research assistants for more than seven months and up to a year. We had conversations with all participants in person, participated in the whole seven-month internship, and conducted individual interviews with the participants before and after the internship. For the criterion of persistent observation, we observed all activities, took field notes, and videorecorded the whole internship. By discussing research questions and findings with peers who had no contractual interest in the situation (i.e., disinterested educational researchers who did not participate in the study), we tested working hypotheses through peer debriefing. Through continuous discussions with our peers, the findings emerged and were constantly adjusted. The gradually developing process of generating research questions and findings allowed us to reduce privilege and meet the criterion of progressive subjectivity. Moreover, to enhance credibility, we triangulated our data analysis with different data sources, including different stakeholders' interviews, students' journals, internship videos, observations, and their field notes.

\section{FINDINGS}

To illustrate the contradictions in the activity systems, we selected two case studies: a psychology group and a chemistry group. For each group, we demonstrate how students and scientists first identified contradictions during cogens and then transformed these contradictions by discussing them in depth in cogens and implementing solutions in practice. 


\section{Psychology Group: Daisy, Ruby, and Dr. Muller}

The members of the psychology group included two students, Daisy and Ruby, with the support of Dr. Muller, an assistant professor in clinical laboratory sciences. Daisy and Ruby were interested in psychology so they pursued a research project to investigate the relationship between human senses and consciousness. During the scientific inquiry in the PBL-based internship, Daisy and Ruby experienced a series of challenges while working on their projects. In the following sections, we demonstrate how they identified contradictions in their internship through cogens and how they transformed these contradictions through collective efforts in cogens and practices.

\section{Contradiction between subject and object: What will be our project topic?}

Identifying the contradiction. In the program, students were expected to develop their own research topics (object) which should be real-life problems with frames of reference and motivate them to find solutions. However, after a series of lectures, hands-on activities, and an invitation to brainstorm their project ideas, students still did not know what to do. In one cogen, students brought up their concerns about finding possible topics: "I wonder how to think about what type of project. And we don't know exactly what we're supposed to be thinking about." To address students' concerns, Dr. Muller explained: "My department is medical lab science. So pretty much anything that ties into immunology, microbiology, serology, urinalysis, chemistry, molecular biology...you're actually probably one of the few groups who has the ability to choose just about anything you want with the exception of physics. So there is really no limitation on what you want to choose." These conversations in cogens helped students identify the contradiction of subject and object (i.e., students' challenge of finding project ideas) and communicate this contradiction to their scientist, who then had a chance to address the contradiction. This contraction is secondary in nature, as defined by activity theory, because it exists between the constituent moments of subject (i.e., internship students) and object (i.e., research project ideas and knowledge).

Transforming the contradiction. At first, Dr. Muller told students what types of research topics they could choose (e.g., immunology), but some students said they did not know what immunology is. Then, Dr. Muller prioritized the steps of developing a research topic for the students, including thinking about what topic interested them, finding like-minded peers to work with, narrowing down their broad interests into one specific topic, and brainstorming an actual question to which they wanted to find the solution or answer. Out of all these tasks, Dr. Muller emphasized that to find what they really cared or were passionate about was the most important step when deciding their research topics. After understanding the steps of developing their research topic, Daisy and other students started having discussions about their solutions (e.g., through GroupMe).

\footnotetext{
"My main concern is, I remember Dr. Muller was stressing that make sure whatever project you do, that you really like doing it... I'm afraid that you cannot divide up the groups, in a sense that everybody's gonna love their topic... I'm afraid what I really want to do is not gonna be what the other two might want to do. I'm just really concerned about the topics and how it's gonna be divided." (Daisy)
}

Dr. Muller agreed that it was a good idea to identify group members since students had already started discussing this issue with each other. Then, a student suggested that everyone would need to compromise in order to select the topic that fitted most people's interests. Another student shared her experience of finding someone who had similar interests and how they planned to combine their interests in one topic without the major issues that others were concerned about. Finally, a student came up the idea of creating a survey online through the GroupMe application to share their ideas via cellphones. Dr. Muller asked students to write down three possible ideas of areas that they would be interested in working on after their discussions via GroupMe.

After a series of cogen discussions on research topics, Dr. Muller understood that students still had a hard time deciding on their research topics because they did not know which ideas were valid as a research project. To help students get a sense of what a research project is, Dr. Muller introduced students to a tool that researchers often use called PubMed, a biomedical literature website where students can navigate various scientific topics they like as exemplary projects. With the help of PubMed, students were able to communicate more effectively with each other about possible research topics. The following were their comments after using PubMed:

Daisy It was kind of a realization to think...it's one thing to have an idea. But it's another thing to know what you're doing...Today was just a realization of how much work is needed to be done. And like you can't have just an idea and that's it.

Student D I think it was helpful that Dr. Muller...he was able to show us the website instead of using Google and going to the [PubMed] websites...I think the article actually helped out with the project and everything. So you can actually get some real information...you know how the website sells stuff 


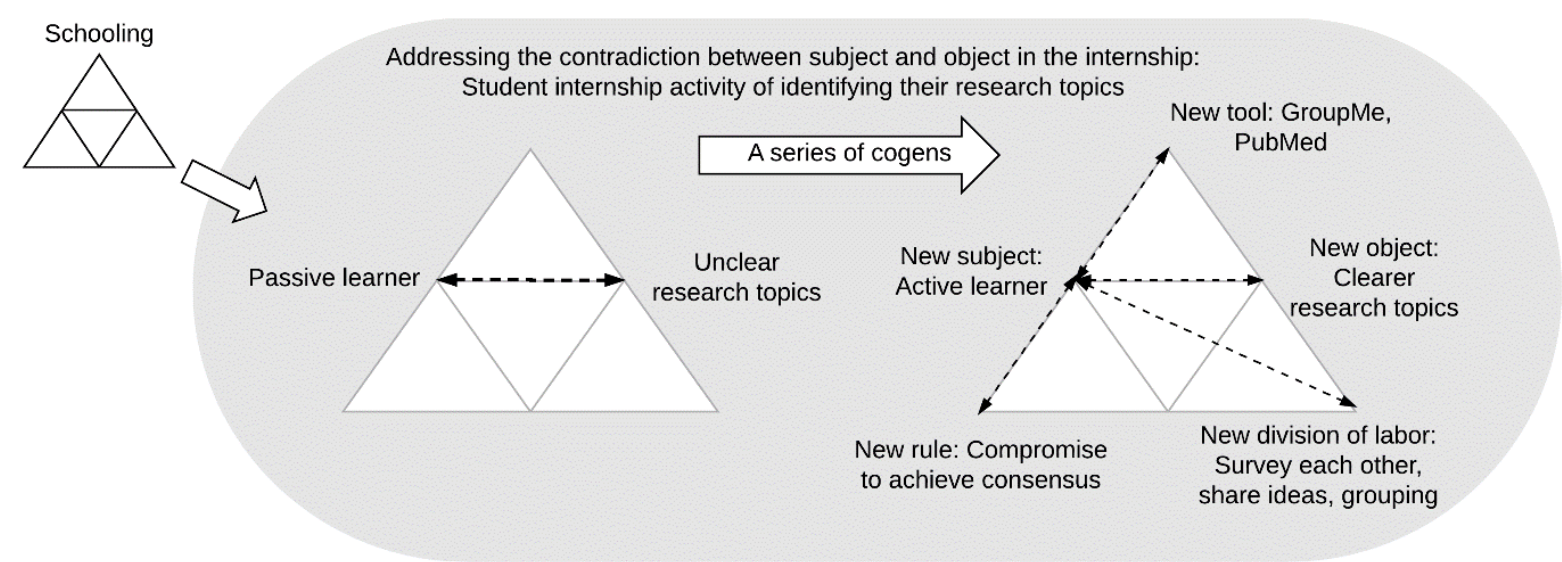

Figure 2. Using cogens to address the secondary contradiction between subject and object

but not like go into detail? That he showed us the website where we can actually see the scientist actually about what you want to do for a project.

Student E I agree with that too because honestly if we will have to do the research as far as typing it in to the Google box because that's what I was doing at first [be]cause I didn't think of looking at that link and going to PubMed...I think it will make the process of finding different references a lot more easier on all of us.

Student F This [PubMed] can help with our project...interesting stuff that we can add to be a project. It's very helpful.

Student G I know what to do now. Last time I was really lost. Now I can like narrow it down to more specific air pollution and stuff like that. Those really help. [Be]cause back then it was really...I didn't know where to look for, you know? It just feels good like now I can actually get my stuff together and find good stuff, like doing research. So, I'm happy about that.

From the episode above, it shows that students learned a new tool (PubMed) to navigate possible research topics and find relevant references, instead of using a familiar but inefficient tool (i.e., Google). These cogens helped students address the contradiction of object (difficulty of finding project topics) and brainstorm various ways to transform the contradiction, such as listing and surveying all possible ideas via a cellphone application (GroupMe) and learning a professional tool (PubMed) to navigate research topics. After a series of communications, students started to form their groups. Daisy and Ruby decided to work together because of their common interest in psychological research on the relationship between human senses and subconscious choices.

An activity transformation of using cogens to address the contradiction between subject and object in the internship is illustrated in Figure 2. When being asked to decide their research topics, students had difficulties to generate research topics and plans on their own since they were used to be told what to do and how to learn as passive learners (Hao et al., 2016). Thus, students encountered a contradiction between subject (i.e., passive learner) and object (i.e., unclear research topic) in the PBL-based internship context. During a series of cogens, students brainstormed solutions and started to use new tools (e.g., GroupMe, PubMed), a new division of labor (i.e., sharing ideas with each other), and a new rule (i.e., agree to compromise in order to achieve consensus for finalizing research topics). As a result of transforming these contradictions through cogens, students became more active learners who know how to generate their research topics as a group.

\section{Contradiction between subject and rule: When will the IRB approval be granted?}

Identifying the contradiction. Since Daisy and Ruby's research project was related to human subjects, they needed to apply for Institutional Review Board (IRB) approval to ensure their research protocol complied with ethical practices. With the guidance and support of Dr. Muller, they successfully submitted their IRB application for review. However, Daisy worried about the waiting time for IRB approval which might delay their experiments to complete their projects on time.

Daisy It's just that my concern is kinda the IRB approval, and how, like, involving the testing schedule. [Be]cause like, I mean, it's not up to us. It's out of our control. As to when it's gonna be approved. So I'm afraid it might affect your testing schedule, maybe you know just in general. And I'm kinda concerned that if it does lead up to the fact...change the angle of our project, could we? 
Dr. Muller You know that's a very valid concern that you have, actually. It, it's very important that you think about that because, really, time management is important and knowing to have enough time...it's really great actually that you're thinking about that because that shows foresight and consideration...five weeks, that's plenty of time. We'll have no worries to, you know, to get stuff done. But now you're kinda seeing that four weeks is not that long.

Daisy I was just very concerned.

Dr. Muller But, yes, we can figure something out. There's always something you can do.

Dr. Muller agreed with Daisy and validated her concern by recognizing her foresight and consideration. This cogen conversation helped students express the contradiction between subject (students' plan) and rule (IRB approval) and led to a discussion with Dr. Muller about possible modification of their project if the IRB approval was granted late. This contraction is secondary in nature, as defined by activity theory, because it exists between the constituent moments of subject (i.e., internship students) and rule (i.e., research practice rules).

Transforming the contradiction. While waiting for the IRB approval, Daisy expressed her concern about the possible need to modify the project due to late IRB approval. Daisy had some preliminary idea of using the data from other studies but she did not know if her idea was doable until Dr. Muller told her that is called meta-analysis. Dr. Muller explained that meta-analysis would not require IRB approval. He said that they could do meta-analysis while waiting for IRB approval, since eventually students could publish either one of the results or both of them.

Daisy Since I will be leaving, I'm kind of just setting up-well, when we do get the approval let's do this...we've changed our schedule and we've even thought of a possible plan B is if our approval came in too late. In the sense that, we could look at other data from other things...we're kinda planning for the good and the bad. So, that's what we're focusing on... I mean this is something that has been done before...we're kinda thinking to ourselves like if this [IRB] doesn't work we have to think of something else, but we'll be fine.

Dr. Muller One of the options we could do, and you don't need approval for this, is to do what's called a metaanalysis, M-E-T-A. And what that means is you're not doing the analysis yourself but you're analyzing secondary data that other people analyzed. And you could actually be doing that while you're waiting on the [IRB] being approved. And you could publish both of those things.

Daisy So, I mean, we've been planning and stuff and well I mean we've also been being extremely productive and getting really involved with their group [another group in the same laboratory].

The uncertainty of IRB approval (rule) had affected the planning of Daisy's (subject) group. A week after Daisy raised her concerns about the potential risk of delaying their experiments due to IRB waiting time, Daisy, Ruby, and students in other groups collaborated to identify the data they could use to conduct a meta-analysis. The cogen discussion about the contradiction of subject and rule created an opportunity for students to acquire in-depth understanding of how other types of research methods existed (e.g., meta-analysis). Daisy and Ruby not only started thinking creatively, but also developed autonomy to manage their project and utilize their waiting time for learning.

An activity transformation of using cogens to address the contradiction between subject and rule in the internship is illustrated in Figure 3. While waiting for their IRB approval for their research, Daisy and Ruby became anxious because they did not know whether and when the approval would be granted. Thus, students encountered a contradiction between subject (i.e., anxious researcher) and rule (i.e., uncertainty of IRB approval) in the PBLbased internship context. After a series of cogens, students brainstormed solutions (i.e., conduct meta-analysis as Plan B) and enacted both a new division of labor (i.e., work with other groups and share their data) and a new rule (i.e., embrace the possibility of using existing data for research). As a result, students had a backup plan in mind and became calmer. 


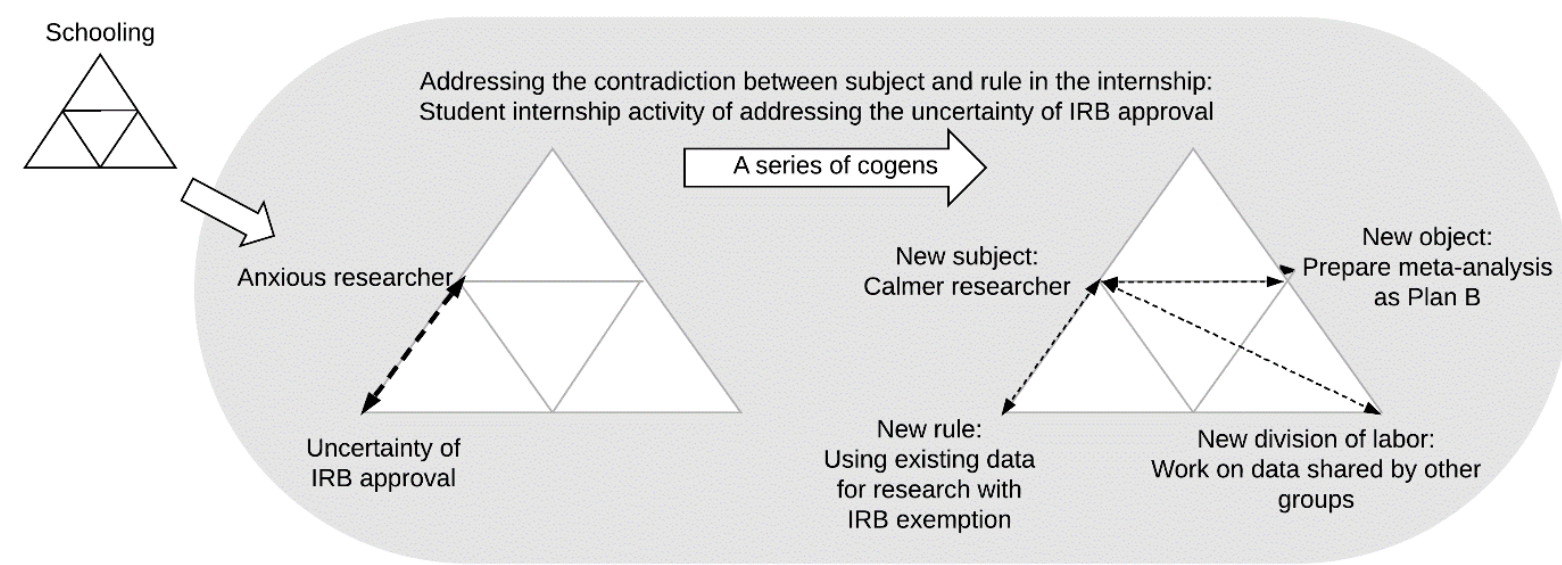

Figure 3. Using cogens to address the secondary contradiction between subject and rule

\section{Chemistry Group: Vicky, Aaron, Yong, and Dr. Sanchez}

The members of the chemistry group included three students, Aaron, Vicky, and Yong, with the support of Dr. Sanchez, an assistant professor in chemistry. Aaron, Vicky, and Yong's project was to investigate possible chemical solvents to treat Parkinson's disease. During the scientific inquiry in the PBL-based internship, Aaron, Vicky, and Yong experienced a series of challenges while working on their project. In the following sections, we demonstrate how these students identified their contradictions during cogens and how they transformed these contradictions through collective efforts in cogens and practices.

\section{Contradiction of subject: How to be critical thinkers?}

Identifying the contradiction. PBL facilitates the adoption of skills associated with self-regulated learners (Savin-Baden, 2007; Stefanou et al., 2013), so students are expected to ask questions and exercise critical thinking. However, one of the challenges in PBL is that students have grown accustomed to a passive learning environment in which they follow instructions from authority figures (Hao et al., 2016). As a result, after a series of lectures and activities, Dr. Sanchez articulated that students quickly accepted everything they learned without much questioning. Thus, he brought up his concern in one cogen: "I think we need to engage more some of the student thinking about the topic of the day... The thinking for me is deeply thinking about why those two solvents will like each other, why [it is the] mechanism behind or rationale behind the why. The question is why. It's not just accepted [that] one plus one equals two, but indeed it equals two because it makes sense." After listening to Dr. Sanchez's concern, students started to explain the reasons behind this situation. A student said that they had the "habit" of receiving information from school teachers and they were used to not questioning why. Another student added that they usually accepted whatever their teachers said because they believed that they should always listen to their teachers in schools. This cogen alleviated Dr. Sanchez's concern and helped him communicate with students about what he expected from them. Meanwhile, this cogen also allowed students to explain their learning habits (e.g., passively receiving information from instructors rather than questioning it) to the scientist who did not understand why students accepted everything he said without questions. This contraction is primary in nature, as defined by activity theory, because it exists in one constituent moment of the subject (i.e., internship students).

Transforming the contradiction. After understanding Dr. Sanchez's concern of expecting students to be critical thinkers, students tried to ask questions during the internship. However, asking questions itself was quite challenging for students. Thus, during cogens, students started to analyze the situation, identify issues, and brainstorm ways to help themselves get into the habit of being critical thinkers.

Student H I feel like another issue may be that sometimes when you're learning something, sometimes you don't get it right away. Like you don't understand it completely, but everybody else does, so sometimes you feel like you should agree, too, because you're like...everybody else gets it, I don't...Sometimes I feel like that...the process is too fast so maybe it should slow down because others don't really voice their opinions.

Vicky Yeah, [be]cause I needed more explanation because...I don't wanna be the only person that says I don't know what's going on. 
Cogen So I think the pace, I think asking questions on top of thinking critically is a perfect solution for the mediator issue that we had of it being too fast and not understanding. Does anybody else have or want to add to that?

Aaron I was trying to go back to... but I was like, I don't wanna backtrack anybody [be]cause it was like two [slides?] above... So I was like Oh, boy, should I ask, should I not ask?

Cogen So we're touching base on an issue-one, was the pace just too fast and two, because it was just all mediator audio. You weren't actually having something visual.

Aaron I'm a big visual.

Dr. It's in the plan to do a demo during the first hour to see it... But we need to get some theoretical Sanchez knowledge... it's good that you brought that you need paper to read. Do you know, it's so much important to see how I can hit your brain and excite them asking something that you never heard about, and then just giving you a tool, a computer, and the feedback and reaction... It is exciting for me to see that at least you get that $50 \%$ from my class at least using whatever I decided to guide you to use... Maybe I know a little bit better, but at least I saw a lot of you good feedback. So congratulations on a positive note... However, there will be, uh, things to improve and if we want you... maybe you want those papers, we will give them. We can email our presentations actually at the end of the day, not before, because I want you to be more focused on all what we're saying. We could provide it to you, but I thought I could use the high tech in the computer and the access to internet and search. There was a few key points that I was focusing on to see. Good that I hear all the critiques. We can improve as much as we can, and I would like to see more critiques.

Vicky I don't think it's so much we want a paper in front of us... I just kind of want to see how it goes... [be]cause outlines I feel like we're just still being told the same thing.

Dr. Maybe we can bring it here if you want to... Don't get worried or scared about wording because it's Sanchez on you... I'm just initiating something on you, right?... Think about it. I never heard 100\% from a lecture so I go back and that lecture will initiate something and focus my interest, so homogeneous or heterogeneous, you're still confused? Go back, use the Google, search and find out, with pictures. Teach yourself, I guess that's the take-home message.

Research Oh, I was just gonna say that if you guys feel like we're going too fast or we're going - something's assistant confusing and we just flew by it, just let us know, I mean, we will all appreciate... We'll make sure to stop and go back and repeat to you guys what's happening, because if someone is not getting it, that means somebody else in the classroom isn't getting it. So we want to have everyone on the same level, okay?

One student said that sometimes students might be confused by new concepts and not want to ask questions, because all the other people seemed to agree with what they were told. He also felt sometimes the pace was too fast for him to absorb new knowledge. Vicky also said that she needed more explanation and she did not want to be the only student who pointed out that she did not understand the new concept. Aaron then also described that sometimes he hesitated to ask questions because the PowerPoint slide he did not understand had passed. The cogen mediator then summarized the issues of fast teaching pace and the lack of visuals in lectures. Dr. Sanchez said that he and his RAs did prepare a demo to be used later in the lab, but they wanted students to have a basic understanding first. He was glad to see that students were asking for more material (e.g., handouts, computer) to help themselves understand the concepts. Vicky explained that she did not mean more handouts to read; instead, she wanted to see more visuals (e.g., pictures or actual experiments) so she could see the process of mixing liquids. Dr. Sanchez said that they would try to bring the actual materials to the meeting, and he told students not to feel scared to ask for help from them. Meanwhile, he shared his own learning experience to let students understand that sometimes they would need to study a bit more at home instead of expecting to understand everything in a short period of class time, because self-teaching was also important. One research assistant also encouraged students to ask questions or seek clarification any time they felt they needed to. In summary, these cogen conversations helped participants analyze their own learning habits and suggested possibilities to help students become critical thinkers, including slowing down the teaching pace, presenting with visual aids, and studying at home.

An activity transformation of using cogens to address the contradiction of subject in the internship is illustrated in Figure 4. While working in the internship, students often passively received information from the scientists and did not think critically, because students usually took instructors' information as knowledge without questioning it. Thus, students encountered the contradiction of subject (i.e., uncritical learner) in the PBL-based internship context. After a series of cogens, students brainstormed solutions and adopted new tools (i.e., including more visual aids in teaching), enacted a new division of labor (i.e., teachers teach with slower pace and students study at home), 


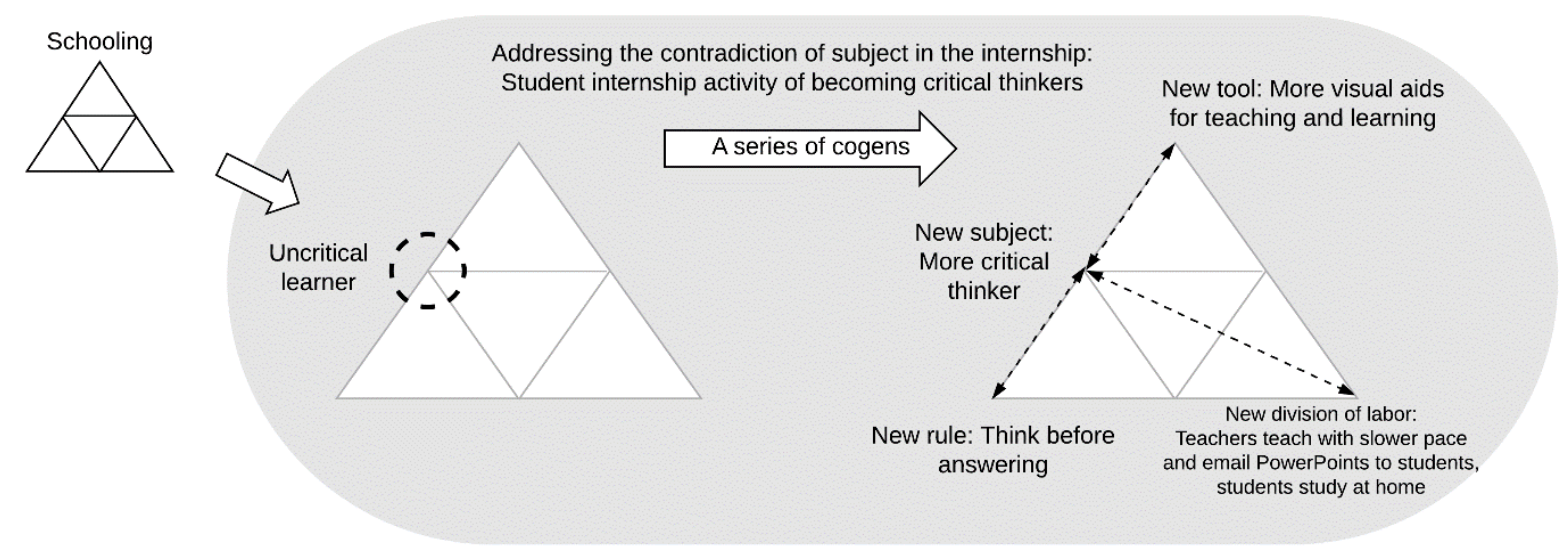

Figure 4. Using cogens to address the primary contradiction of subject

and adopted a new rule (i.e., think before answering the instructor's questions). As a result, students gradually became more critical thinkers in the internship.

\section{Contradiction between subject and community: How to collaborate successfully for scientific research?}

Identifying the contradiction. In this PBL environment, students were expected to collaborate with others to complete their scientific projects collectively. However, collaboration seemed to be challenging for students due to communication difficulties. In several cogens, communication issues were brought up many times. Communication covered many levels, including communication within the small groups and between the students and instructors.

"I thought communication was really bad [in our group]... We had the Google Docs. And an issue with myself is I never used Google Docs before. And so I didn't know what I was doing... I was stressing out. Like everything we had actually still had to do, nothing's done, and so we all agreed to meet up on Sunday, but nobody texted each other... And we had three separate PowerPoints when we got in here. The problem that we had was we had to combine all of them into one. I think that's just really stressful. Because there's no communication and I mean, I thought we needed more time because I was freaking out." (Vicky).

During cogens, communication problems were constantly brought up in order to brainstorm ways that the group could solve them. This contraction is secondary in nature, as defined by activity theory, because it exists between the constituent moments of subject (i.e., internship students) and community (i.e., research collaborators).

Transforming the contradiction. To address communication issues, many different solutions were proposed in cogens and implemented in practice. If one method did not work, participants would bring it to cogens for discussion and brainstorm new ways to improve their communication.

"I feel that we should start communicating or at least text messaging every day. That would have been a lot less stressful." (Vicky)

"If we had the communication better, and if we had the line by line comments on the feedback by our RAs, so they could explain whatever confused us at that point so we would be better prepared for the next [time]." (Aaron)

"So that's an alternative way for the team who cannot meet, you can create a virtual meeting where you just reply to that email. Maybe ten minutes, look it, evaluate, and shout your opinion, and it's gonna circulate...but rather I'd like also to mention that we need a team leader to say or take over that, like [what] your research assistant is doing...I think in addition to meeting physically, I also favor the option if we cannot meet, [we should] look at other ways that provide feedback. You will want to improve your communication style, writing, and also voice not in front of the person by email. That's one option also that we could consider because we have to keep going, the project, and communication is the key." (Dr. Sanchez)

An additional contradiction between subject and community in the internship was collaboration with other laboratory teams. Students in Dr. Sanchez's group were approached by students in another laboratory (neurology) 
and asked to share their project information with them. Students were confused about this request and hesitated to share their project information with them. They brought up the issue in cogens for discussion.

Yong The neurology lab wanted to use our information with theirs for their brain tissue that they wanted to experiment.

Dr. Sanchez This is actually interesting. At this level, they're starting to knock on doors and take initiative and look for collaborations. So imagine that at another age, I am amazed the way how they approached you. They learned that our lab is doing plants, and they're interested to evaluate that. That's great. That's what I call a real scientist.

Vicky I kinda complained a bit about it...what they're doing is like taking what we use and just use it as theirs - and then making a project off of our work. And so that, that was my major issue.

Aaron The only thing that I was like apprehensive about was like more people involved means like I have to depend on more people.

Vicky And then what if like they would've like put the blame on us...?

Dr. Sanchez Let me ask you all a question. You spend a lot of time in extracting that, and you prefer freeze it in the fridge than use the expertise of somebody else to evaluate the effect of that? Or you want to spend the next year learning that assay or the technique to validate or to test your plant? Which one do you prefer? And second question is, do you know what is collaboration definition means?

Vicky I know what collaboration means. It's more of the fact that I felt as if they weren't gonna put the effort in the work... I felt that they didn't do enough research on the background... If they would've asked us more in-depth questions, that I would've been, “Okay yeah, let's collaborate."

Yong I said it really doesn't matter [be]cause they're gonna end up putting our work on it so they're gonna give us like the credit that we gave them that information.

Dr. Sanchez Yes indeed. It doesn't take your work, hard work, away, right?

Vicky I would've been happy for it if it was like if I would've have more information. They didn't give us any.

Dr. Sanchez Sure. But you can ask for that. I still think that you can always take a lead and ask... But that's good that you brought this today because the earliest is the better, then you go back and realize you want to work in the future in a science environment, this is how it's gonna work. I cannot have the expertise of everything, same you. So you will be focusing on something and have collaborators that have different expertise to help you and at the same you help back. It's not one way, okay? It's both ways.

A contradiction existed between subject and community, because Vicky and some students felt it would not be fair to take away their hard work to help another laboratory that might not have put in the same efforts as they did. Dr. Sanchez, however, assured students that they could ask the neurology lab for more information if they felt they needed it, instead of being passive about it. Also, he explained to them that the importance of collaboration was that each party would get benefits from it, especially students who wanted to work in a science environment in the future. After Dr. Sanchez explained what collaboration meant in science and why it was important to learn from others' expertise through collaboration, students became more welcoming of collaboration between labs, instead of wondering if there would be negative impacts.

An activity transformation of using cogens to address the contradiction between subject and community in the internship is illustrated in Figure 5. In the PBL-based internship, students were expected to collaborate for research. However, students usually worked alone and did not have effective collaboration with others. Thus, students encountered a contradiction between subject (i.e., independent researcher) and community (i.e., community without effective collaborations) in the PBL-based internship context. After a series of cogens, students understood the need for and value of collaboration. In addition, they redefined the nature of community (e.g., seeing other laboratory teams as collaborators), adopted new tools (e.g., virtual meetings, emails), enacted a new division of labor (e.g., have different roles for each team member, exchange beneficial information with other groups), and used a new rule (i.e., agree to have frequent communication). As a result, students gradually became more collaborative researchers in the internship. 


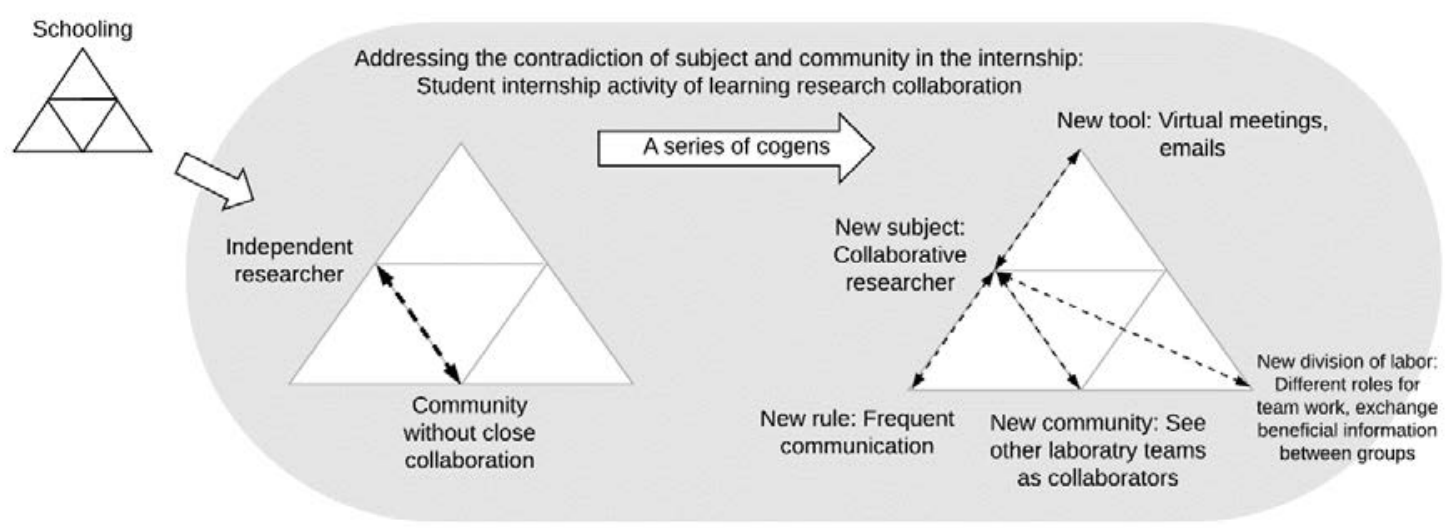

Figure 5. Using cogens to address the secondary contradiction between subject and community

\section{DISCUSSION}

Studies show that the use of a project-based science approach makes authentic science accessible by situating scientific practices in a meaningful context and activities (Krajcik \& Blumenfeld, 2006). Although science educators encourage content-rich inquiry learning and thinking in authentic contexts, "the nature in which features of the authentic contexts should be transformed to support inquiry thinking is still far from understood" (Lee \& Butler, 2003, p. 928). To address important aspects that ensure the effectiveness of PBL requires aligning project complexity to students' levels, providing proper assistance, assessing students' prior knowledge, and increasing students' teamwork skills (Tseng et al., 2013). Researchers have called for studies to illustrate how teachers and students can create contexts that support PBL approaches (e.g., perceived classroom goal structure, grouping practices) for teachers to create challenging work in collaboration with their students (Meyer et al., 1997). Drawing on culturalhistorical activity theory, our analysis suggests that cogens can serve as a practical instructional design and pedagogical tool to help high school students and scientists address the contradictions and challenges they encounter in the process of teaching and learning in PBL environments.

The two case studies in our empirical study illustrate how cogens can be a supportive space in which to address challenges in PBL by identifying and transforming contradictions in the PBL-styled student-scientist partnership program. Contradictions are valuable in the learning process because they assist in the overall transformation of the activity system (Farrar, 2016). For transformation to occur, contradictions must be recognized and reflected and acted upon. In the psychology group, cogens allowed students to express their concerns and reflect on their challenges in PBL with their instructors and peers (e.g., not knowing how to identify research topics, anxiety about the uncertainty of IRB approval). Through collective dialogues, students gradually identified possible solutions and eased their anxieties. In the chemistry group, the scientist pointed out the need for students to become critical thinkers and team players in the PBL-based internship. Through collective dialogues, students and instructors brainstormed ways to transform their teaching and learning practices, and students were gradually empowered to form new identities as critical thinkers and team players. As one of the students' journal entries illustrated, cogens helped participants address and reduce problems in the internship as time went by: "As weeks progress, we are slowly overcoming many of our problems and are continuing to better our problems and therefore we are coming across less and less [problems] every week."

Our empirical study demonstrates how participants used cogens to analyze and dissect the challenges in the authentic context of university scientific research and to transform their practice through collective efforts of brainstorming, implementing, and reflecting on these ideas and solutions. The role of cogens in our studentscientist partnerships was important because students worked at the elbows of scientists for a long period of time. Often, scientists have challenges with communicating science to the public, mostly due to the complex language of scientific jargon and terminologies (Peters, 2013). To work with students more effectively, scientists need support and help in learning to work with K-12 students (Feldman \& Pirog, 2011), because scientists and students are two distinct groups that possess fundamentally different kinds of understanding of complex systems. The purposeful discussion about various contradictions in cogens allowed participants to deeply reflect on their understandings about learning, teaching, and scientific practice and even to disrupt their existing paradigms (Amory, 2010) to negotiate new meanings and understandings that supported students' science learning. These findings suggest that cogens can serve as a pedagogical tool for bridging two distinct groups of stakeholders (e.g., students and scientists) to cross boundaries (e.g., schooling and research in laboratories) and build connections (e.g., stronger bond) in order to enact cultural border crossing (Aikenhead \& Jegede, 1999). 
Moreover, cogens may help students to learn science more authentically because the "design and development of authentic science activities involve the transformation of complex and ambiguous content, scientific thinking skills, and resources that support scientific investigations" (Lee \& Butler, 2003, p. 924). Through cogens, various challenges in PBL can be transformed and addressed according to participants' needs and solutions. As a result, students and scientists, with the support of cogens, may achieve "contextually authentic science inquiry" (Buxton, 2006) that values the complex and multifaceted nature of interactions among learner, task, and environment.

Furthermore, the findings of this study can serve as resources for science teacher education programs and professional development programs for science teachers to learn the use of cogens in their teaching practice. Research has found that although preservice and in-service teachers find value in inquiry-based science (e.g., PBL), their teaching practices in schools are not consistent with inquiry-based science (Brown \& Melear, 2006). Meanwhile, creating a learning environment that promotes students' autonomy still challenges teachers from K16 (Stefanou et al., 2013). As illustrated in this study, cogens can serve as a pedagogical tool to create a constructivist learning environment where students are empowered to express their voices and concerns. In that way, cogens foster agency and structure that allow students to learn science constructively.

\section{CONCLUSION}

In this study, we pioneered the use of cogens in student-scientist partnerships to support project-based learning (PBL), a student-centered learning environment that involves complex knowledge, skills, and interactions. To understand how cogens may address challenges in PBL, we drew on cultural-historical activity theory to analyze the real-time conversations in cogen sessions. Based on our analysis of two case studies, we demonstrated how cogens can help both students and teachers to identify contradictions in the internship activity and transform these contradictions through a series of genuine conversations in cogens. In these conversations, participants reflected on their thinking and practices, communicated their different perspectives, and eventually achieved consensus regarding action plans to address the contradictions. Our findings suggest that cogens can serve as a practical instructional design and pedagogical tool to address the challenges and contradictions high school students and scientists encounter in PBL, transform those contradictions into teaching and learning opportunities, and empower students to learn science constructively in a PBL environment. Future educators may adopt cogens in other educational settings, such as schools, where teachers wish to create a PBL environment for their students to engage in scientific practices. Future researchers may also conduct experimental studies to investigate the impacts of cogens on students in PBL environments, including, for example, the impact on students' attitudes, knowledge, research skills, interests, views about the nature of science, problem-solving skills, and critical thinking.

\section{ACKNOWLEDGEMENT}

This work was supported by the National Science Foundation under Grant No. DRL 1322600. Any opinion, findings, conclusions, or recommendations expressed in this material are those of the authors and do not necessarily reflect the views of the National Science Foundation.

\section{REFERENCES}

Aikenhead, G. S., \& Jegede, O. J. (1999). Cross-cultural science education: A cognitive explanation of a cultural phenomenon. Journal of Research in Science Teaching, 36(3), 269-287. https://doi.org/10.1002/(SICI)10982736(199903)36:3<269::AID-TEA3>3.0.CO;2-T

Amory, A. (2010). Education technology and hidden ideological contradictions. Journal of Educational Technology $\mathcal{E}$ Society, 13(1), 69-79. Retrieved from http:/ / www.jstor.org/stable/jeductechsoci.13.1.69

Babco, E. L. (2004). Skills for the innovation economy: What the 21st century workforce needs and how to provide it. Commission on Professionals in Science and Technology.

Brown, S. L., \& Melear, C. T. (2006). Investigation of secondary science teachers' beliefs and practices after authentic inquiry-based experiences. Journal of Research in Science Teaching, 43(9), 938-962. https:/ / doi.org/10.1002/ tea.20110

Buxton, C. A. (2006). Creating contextually authentic science in a "low-performing" urban elementary school. Journal of Research in Science Teaching, 43(7), 695-721. https:/ / doi.org/10.1002/ tea.20105

Cardoso, C., Eriş, Ö., Badke-Schaub, P., \& Aurisicchio, M. (2014). Question asking in design reviews: How does inquiry facilitate the learning interaction? In Design Thinking Research Symposium. West Lafayette, IN: Purdue University. https:/ / doi.org/10.5703/1288284315941 
Chinowsky, P. S., Brown, H., Szajnman, A., \& Realph, A. (2006). Developing knowledge landscapes through project-based learning. Journal of Professional Issues in Engineering Education and Practice, 132(2), 118-124. https:/ / doi.org/10.1061/(ASCE)1052-3928(2006)132:2(118)

Corbin, J. M., \& Strauss, A. L. (2015). Basics of qualitative research: Techniques and procedures for developing grounded theory. Thousand Oaks, CA: SAGE.

Emdin, C. (2011). Citizenship and social justice in urban science education. International Journal of Qualitative Studies in Education, 24(3), 285-301. https:/ / doi.org/10.1080/09518398.2010.539582

Engeström, Y. (1987). Learning by expanding: An activity-theoretical approach to developmental research. Helsinki, Finland: Orienta-Konsultit Oy.

Engeström, Y. (1996). Developmental work research as educational research: Looking ten years back and into the zone of proximal development. Nordisk Pedagogik: Journal of Nordic Educational Research, 15(5), 131-143.

Engeström, Y. (2001). Expansive learning at work: Toward an activity theoretical reconceptualization. Journal of Education and Work, 14(1), 133-156. https:/ / doi.org/10.1080/13639080020028747

Engeström, Y. (2008). From teams to knots: Activity-theoretical studies of collaboration and learning at work. Cambridge, UK: Cambridge University Press. https:// doi.org/10.1017/CBO9780511619847

Engeström, Y. (2015). Learning by expanding: An activity-theoretical approach to developmental research.

Farrar, C. H. (2016). Teachers' instructional goals for science practice: Identifying knowledge gaps using cultural-historical activity theory (CHAT) (Doctoral dissertation), Columbia University. Retrieved from https:/ / search.proquest.com/docview/1791131298/abstract/659FA9C4D9A64E3APQ/1

Fayer, S., Lacey, A., \& Watson, A. (2017). STEM occupations: Past, present, and future. Spotlight on Statistics. Retrieved from https://pdfs.semanticscholar.org/82c3/4b06c6aa1ac049349658ce9037e72fcf5b46.pdf

Feldman, A., \& Pirog, K. (2011). Authentic science research in elementary school after-school science clubs. Journal of Science Education and Technology, 20(5), 494-507. https:/ / doi.org/10.1007/s10956-011-9305-4

Foot, K. A. (2014). Cultural-Historical activity theory: Exploring a theory to inform practice and research. Journal of Human Behavior in the Social Environment, 24(3), 329-347. https:/ / doi.org/10.1080/10911359.2013.831011

Guba, E. G., \& Lincoln, Y. S. (1989). Fourth generation evaluation. Newbury Park, CA: SAGE.

Hao, Q., Branch, R. M., \& Jensen, L. (2016). The effect of precommitment on student achievement within a technology-rich project-based learning environment. TechTrends, 60(5), 442-448. https:// doi.org/10.1007/s11528-016-0093-9

Hsu, P.-L. (2018). Strategies to mediate cogenerative dialogues between scientists and high school students. Paper archived in the 2018 AERA Online Paper Repository.

Hsu, P.-L., \& Espinoza, P. (2018). Cultivating constructivist science internships for high school students through a community of practice with cogenerative dialogues. Learning Environments Research, 21(2), 267-283. https:/ / doi.org/10.1007/s10984-017-9253-x

Krajcik, J. S., \& Blumenfeld, P. C. (2006). Project-based learning. In R. K. Sawyer (Ed.), The Cambridge handbook of the learning sciences (pp. 317-334). Cambridge, UK: Cambridge University Press.

Krajcik, J. S., \& Czerniak, C. M. (2014). Teaching science in elementary and middle school: A project-based approach (4th ed.). New York, NY: Routledge.

Kuutti, K. (1996). Activity theory as a potential framework for human-computer interaction research. In B. A. Nardi (Ed.), Context and consciousness: Activity theory and human-computer interaction (pp. 17-44). Cambridge, MA: MIT Press.

Lee, H.-S., \& Butler, N. (2003). Making authentic science accessible to students. International Journal of Science Education, 25(8), 923-948. https:// doi.org/10.1080/09500690305023

Leont'ev, A. N. (1974). The problem of activity in psychology. Journal of Russian and East European Psychology, 13(2), 4-33. https:/ / doi.org/10.2753/RPO1061-040513024

Leont'ev, A. N. (1981). Problems of the development of the mind. Moscow: Progress Publishers.

Markham, T., Larmer, J., \& Ravitz, J. (2003). Project-based learning handbook: A guide to standards-focused project-based learning (2nd ed.). Novato, CA: Buck Institute for Education.

Meyer, D. K., Turner, J. C., \& Spencer, C. A. (1997). Challenge in a mathematics classroom: Students' motivation and strategies in project-based learning. The Elementary School Journal, 97(5), 501-521.

Murphy, C., \& Carlisle, K. (2008). Situating relational ontology and transformative activist stance within the 'everyday' practice of coteaching and cogenerative dialogue. Cultural Studies of Science Education, 3(2), 493506. https:// doi.org/10.1007/s11422-008-9124-y 
NGSS Lead States. (2013). Next generation science standards: For states, by states. Washington, DC: The National Academies Press. https:/ / doi.org/10.17226/18290

Osborne, J. (2014). Teaching scientific practices: Meeting the challenge of change. Journal of Science Teacher Education, 25(2), 177-196. https:/ / doi.org/10.1007/s10972-014-9384-1

Patchen, T., \& Smithenry, D. W. (2014). Diversifying instruction and shifting authority: A cultural historical activity theory (CHAT) analysis of classroom participant structures. Journal of Research in Science Teaching, 51(5), 606634. https:// doi.org/10.1002/tea.21140

Peters, H. P. (2013). Gap between science and media revisited: Scientists as public communicators. Proceedings of the National Academy of Sciences, USA, 110, 14102-14109. https:/ / doi.org/10.1073/pnas.1212745110

Radinsky, J., Bouillion, L., Lento, E. M., \& Gomez, L. M. (2001). Mutual benefit partnership: A curricular design for authenticity. Journal of Curriculum Studies, 33(4), 405-430. https:/ / doi.org/10.1080/00220270118862

Roth, W.-M., \& Tobin, K. (2002a). Redesigning an" urban" teacher education program: An activity theory perspective. Mind, Culture, and Activity, 9(2), 108-131. https:/ / doi.org/10.1207/S15327884MCA0902_03

Roth, W.-M., \& Tobin, K. (2002b). At the elbow of another: Learning to teach by coteaching. New York, NY: Peter Lang.

Roth, W.-M., \& Tobin, K. (2004). Coteaching: from praxis to theory. Teachers and Teaching, 10(2), 161-179. https:/ / doi.org/10.1080/0954025032000188017

Roth, W.-M., Lee, Y. J., \& Hsu, P.-L. (2009). A tool for changing the world: Possibilities of cultural-historical activity theory to reinvigorate science education. Studies in Science Education, 45, 131-167. https:/ / doi.org/10.1080/03057260903142269

Roth, W.-M., Tobin, K., \& Zimmermann, A. (2002). Coteaching/cogenerative dialoguing: Learning environments research as classroom praxis. Learning Environments Research, 5(1), 1-28. https:// doi.org/10.1023/ A:1015662623784

Sadler, T. D., Burgin, S., McKinney, L., \& Ponjuan, L. (2010). Learning science through research apprenticeships: A critical review of the literature. Journal of Research in Science Teaching, 47(3), 235-256. https:/ / doi.org/10.1002/tea.20326

Savin-Baden, M. (2007). Challenging models and perspectives of problem-based learning. In E. De Graaff \& A. Kolmos (Eds.), Management of change: Implementation of problem-based and project-based learning in engineering (pp. 9-30). Rotterdam, The Netherlands: Sense.

Stefanou, C., Stolk, J. D., Prince, M., Chen, J. C., \& Lord, S. M. (2013). Self-regulation and autonomy in problemand project-based learning environments. Active Learning in Higher Education, 14(2), 109-122. https:/ / doi.org/10.1177/1469787413481132

Stith, I., \& Roth, W.-M. (2010). Teaching as mediation: The cogenerative dialogue and ethical understandings. Teaching and Teacher Education, 26(2), 363-370. https:/ / doi.org/10.1016/j.tate.2009.09.008

Tobin, K., \& Alexakos, K. (2013). Coteaching heuristics (I Other). New York, NY: The City University of New York.

Tseng, K.-H., Chang, C.-C., Lou, S.-J., \& Chen, W.-P. (2013). Attitudes towards science, technology, engineering and mathematics (STEM) in a project-based learning (PjBL) environment. International Journal of Technology and Design Education, 23(1), 87-102. https:/ / doi.org/10.1007/s10798-011-9160-x

Vygotsky, L. S. (1978). Mind and society: The development of higher psychological processes (M. Cole, Ed.). Cambridge, MA: Harvard University Press.

Worsham, E., Clevenger, A., \& Whealan-George, K. (2016). STEM education discrepancy in the United States and Singapore. Beyond: Undergraduate Research Journal, 1(1). Retrieved from http://commons.erau.edu/beyond/vol1/iss1/3

Yamagata-Lynch, L. C. (2007). Confronting analytical dilemmas for understanding complex human interactions in design-based research from a cultural-historical activity theory (CHAT) framework. Journal of the Learning Sciences, 16(4), 451-484. https:/ / doi.org/10.1080/10508400701524777

Yamagata-Lynch, L. C. (2010). Understanding cultural historical activity theory. In Activity systems analysis methods: Understanding complex learning environments (pp. 13-26). Boston, MA: Springer. https:/ / doi.org/10.1007/978-1-4419-6321-5_2

Zydney, J. M., deNoyelles, A., \& Seo, K. K. J. (2012). Creating a community of inquiry in online environments: An exploratory study on the effect of a protocol on interactions within asynchronous discussions. Computers $\mathcal{E}$ Education, 58(1), 77-87. https:/ / doi.org/10.1016/j.compedu.2011.07.009

\section{http://www.ejmste.com}

